\title{
Resistance to extinction as a function of sequence of intertrial nonreinforcement and level of acquisition
}

\author{
IVAN C. GERARD, JEFFREY A. SEYBERT, and LISA P. BAER \\ University of Missouri, Kansas City, Missouri 64110
}

\begin{abstract}
Two experiments investigated the effects of differential level of acquisition training on resistance to extinction generated by intertrial nonreinforcement (ITN). In Experiment 1, four groups received 18 acquisition trials: One group received a nonreinforced placement after $50 \%$ of the six daily reinforced trials (placement N-length of 1, Group ITN-1), a second group received three consecutive nonreinforced placements after one of the six daily reinforced trials (placement N-lengths of 3 , Group ITN-3), a third group received a 50\% partial reinforcement schedule (Group PRF), and a fourth group received continuous reinforcement (Group CRF). In Experiment 2, the ITN-1, ITN-3, and PRF conditions were again used in an identical procedure except that 48 acquisition trials were given. Following limited acquisition, Group ITN-3 was less resistant to extinction than Group ITN-1, while the reverse was true following extended training. These results suggest that sequence of placements, rather than simply their presence or absence, is an important factor in determining resistance to extinction.
\end{abstract}

It has been reliably demonstrated in instrumental learning studies using rats that direct placements in the unbaited goalbox (known as intertrial nonreinforcement, ITN), when interspersed between continuously reinforced (CRF) running trials, produce greater resistance to extinction $\left(R_{n}\right)$ than that generated by CRF alone (e.g., Brown \& Logan, 1965). Similarly, a combination of reinforced (R) and nonreinforced (N) direct placements (known as intertrial partial reinforcement, ITP), interspersed between CRF running trials, yields greater $R_{n}$ than that produced by CRF (e.g., Seybert, Gerard, Myers, Baer, \& Clipper, 1976). Recently, Capaldi (1971) has proposed that, for the case of ITP, the increased $R_{n}$ is a function of the sequence of $\mathrm{R}$ and $\mathrm{N}$ placements. In other words, this explanation holds that the sequence of placements operates to determine $R_{n}$ in much the same way that $R_{n}$ is determined by the sequence of $R$ and $N$ running trials in a conventional partial reinforcement (PRF) paradigm. In fact, Capaldi (1971) demonstrated that $R_{n}$ was increased as a function of the occurrence of $\mathrm{N}-\mathrm{R}$ transitions (a $\mathrm{N}$ goal event followed by a $\mathrm{R}$ goal event) in the placement schedule. That is, placement $N-R$ transitions were shown to increase $R_{n}$ just as do $N-R$ transitions that occur on running trials.

Given that the sequence of $\mathrm{N}$ and $\mathrm{R}$ placements

A preliminary version of this paper was presented at the annual meeting of the Southwestern Psychological Association, April 1976. I. C. Gerard is currently at the Department of Psychology, University of Nebraska, Omaha, Nebraska. Requests for reprints should be sent to J. A. Seybert, Department of Psychology, C. B. Annex, University of Missouri, Kansas City, Missouri 64110. plays an important role in the extinction effects of ITP, it follows that sequential variables may also determine the $R_{n}$ generated by ITN. There is some recent evidence, however (Seybert, Vandenberg, Wilson, \& Gerard, 1977), that questions whether ITN operates according to these sequential processes. Specifically, in an instrumental escape-learning paradigm, these authors observed an ITN effect like that described above but also noted that the ITN group did not differ, in terms of $R_{n}$, from a group that received off-line ITN placements. Seybert et al. (1977) concluded that possibly a stimulus generalization decrement mechanism, rather than a sequential mechanism, was operating in that situation. Thus, the present experiments were performed to further investigate the mechanism underlying the effects of ITN. Specifically, Experiment 1 examined differential $R_{n}$ generated by short vs. long placement $\mathrm{N}$-lengths (an $\mathrm{N}$-length is a run of consecutive $\mathrm{N}$ trials followed by at least one $\mathrm{R}$ trial) following limited training, and Experiment 2 examined $R_{n}$ under similar N-length conditions following more extended training. In a conventional PRF runway situation, $\mathrm{N}$-length has been shown to interact with level of acquisition. Specifically, after limited training, short $\mathrm{N}$-lengths (on running trials) produce greater $\mathrm{R}_{\mathrm{n}}$ than do long $\mathrm{N}$-lengths, while the reverse is true following extended training (i.e., long $\mathrm{N}$-lengths generate greater $\mathbf{R}_{\mathbf{n}}$ than do short N-lengths; cf. Capaldi, 1967). If reward sequence on placements determines $R_{n}$ in a manner similar to reward sequence on running trials, it would be expected that a similar interaction would be observed if level of acquisition and placement $\mathrm{N}$-length (number of consecutive $\mathrm{N}$ placements) are 
manipulated. On the other hand, if a simple generalization decrement mechanism is responsible for ITN effects, as suggested by Seybert et al. (1977), no differences in $R_{n}$ would be expected since both placement $\mathrm{N}$-length conditions will contain an equivalent number of placements.

\section{EXPERIMENT 1}

\section{Method}

Subjects. The subjects were 40 experimentally naive male albino rats of the Sprague-Dawley strain, purchased from the Holtzman Company. They were approximately 90 days old at the start of training and were randomly assigned to one of four groups $(N=10 /$ group).

Apparatus. The apparatus consisted of a $180-\mathrm{cm}$ long, 13-cm wide, straight alley runway constructed of $1.25-\mathrm{cm}$ pine, painted with alternate vertical black and white stripes $2.2 \mathrm{~cm}$ wide. The runway was divided into a $30-\mathrm{cm}$ start section, a $120-\mathrm{cm}$ run section, and a $30-\mathrm{cm}$ goal section. A tablespoon mounted in the distal end of the goalbox served as the food cup. All sections were covered with hinged hardware cloth tops and were separated by guillotine doors. The subjects' progress in the alley was measured photoelectronically by three .01-sec timers. The start timer was activated by opening the startbox door and stopped by interruption of a photobeam $15 \mathrm{~cm}$ into the alley. Interruption of this photobeam activated the run timer, which was in turn stopped when the animal crossed the second photobeam located $15 \mathrm{~cm}$ in front of the goalbox. The goal timer was activated by the second photobeam and stopped upon interruption of a third photobeam located $8 \mathrm{~cm}$ inside the goalbox.

Procedure. For 7 days after arrival at the laboratory, the subjects were provided food and water ad lib. Following this acclimation period and 1 week prior to the start of training, they were placed on a deprivation schedule that consisted of a daily ration of $12 \mathrm{~g}$ of Purina rat chow with water available ad lib. During the 5 days before the start of the experiment, each subject was handled 5-10 min daily. One day of pretraining, consisting of one reinforced running trial, immediately preceded acquisition training for all subjects. Reinforcement consisted of $1.5 \mathrm{~cm}$ (two pieces approximately $90 \mathrm{mg}$ each) of Startina Hog Starter on both running trials and placements. Nonreinforcement consisted of $15 \mathrm{sec}$ confinement in the unbaited goalbox on both running trials and placements. On goalbox placements the animals were placed directly over the food cup.

Acquisition training for all subjects consisted of 6 trials/day for 3 days, for a total of 18 acquisition trials. Group CRF was reinforced on all acquisition trials. Group PRF received $50 \%$ partial reinforcement on the following schedule: RNRNNR. Group ITN-1 (placement N-lengths of 1) received the following acquisition trial schedule: $R n R R n R R n R(R=$ reinforced trial; $\mathrm{n}=$ nonreinforced placement). Group ITN-3 (placement $\mathrm{N}$-lengths of 3 ) received this schedule of trials during acquisition: RRRnnnRRR. These schedules were repeated on each of the 3 days of acquisition.

Following acquisition training, all subjects received 6 extinction trials/day for 3 days, a total of 18 extinction trials. Extinction trials were conducted exactly the same as nonreinforced training trials during acquisition (for the ITN groups, placements were discontinued during extinction). During both acquisition and extinction, the subjects were run in squads of four, one from each group. The ITI was $4 \mathrm{~min}$ throughout the experiment.

\section{Results and Discussion}

Acquisition. The data from all alley segments in

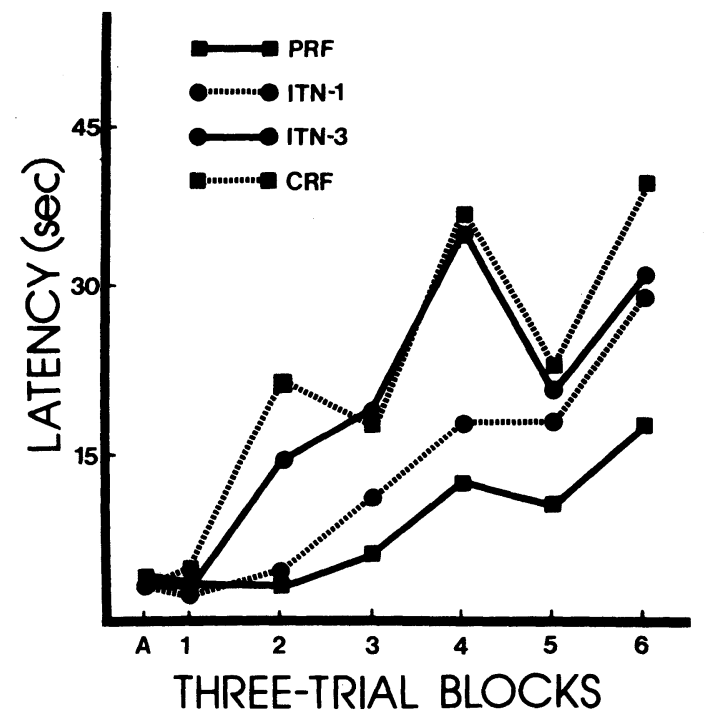

Figure 1. Extinction response latencies in three trial blocks for the PRF, ITN-1, ITN-3, and CRF groups following limited acquisition (Experiment 1).

both experiments produced similar patterns of results, and therefore, only the total latencies (the sum of start, run, and goal times) will be presented and discussed for these experiments. Figure 1 shows that the differences between the four groups at the end of acquisition (Point A) were relatively small. This observation was supported by a one-way analysis of variance conducted on the data from the last day of acquisition $(F<1)$.

Extinction. As is also apparent from Figure 1, the extinction data from Experiment 1 reflect the differences between the ITN-1 and ITN-3 groups and the operation of sequential variables. The data were analyzed via a 4 (groups) by 18 (trials) analysis of variance. The main effects of groups $[\mathrm{F}(3,36)=14.31$, $\mathrm{p}<.001]$ and trials $[\mathrm{F}(17,612)=16.43, \mathrm{p}<.001]$ were significant. The Groups by Trials interaction failed to reach a significant level $[F(51,612)=1.27$, $\mathrm{p}>.05]$. Subsequent planned comparisons (t tests) indicated, as predicted by the sequential hypothesis, that Group ITN-1 was more resistant to extinction than Group ITN-3 $[\mathrm{t}(18)=3.58, \mathrm{p}<.01]$, and that Group ITN-3 was not significantly different than Group CRF $[\mathrm{t}(18)=.971, \mathrm{p}>.05]$. Also Group PRF was more resistant to extinction than Group ITN-1 $[t(18)=2.16, p<.05]$. Thus, the planned comparisons indicated that the groups were ordered PRF $>$ ITN-1 $>$ ITN-3 = CRF, in terms of resistance to extinction. The major finding of the experiment was the greater $R_{n}$ of Group ITN-1 than Group ITN-3. That is, following limited training, short placement N-lengths generated greater $R_{n}$ than did longer placement $\mathrm{N}$-lengths. This finding is analogous to those from similar running trial procedures (cf. Capaldi, 1967) and provides support for the hypothesis (Capaldi, 1971) 
that $R_{n}$ is determined by placement sequence just as it is by sequence of reward on running trials. Experiment 2 attempted to provide further support for this hypothesis by examining the effects of differential placement $\mathrm{N}$-length following more extended training.

\section{EXPERIMENT 2}

\section{Method}

Subjects. The subjects were 30 rats exactly like those used in Experiment 1 . They were randomly assigned to one of three groups prior to the start of the experiment ( $N=10 /$ group).

Apparatus. The apparatus was the same as that used in Experiment 1.

Procedure. Details of the procedure were identical to those for Experiment 1. The groups were identical to those of Experiment 1 except for the elimination of Group CRF.

Acquisition training for all subjects in Experiment 2 consisted of 6 trials/day for 8 days (a total of 48 acquisition trials). As in Experiment 1, Group PRF received a 50\% partial reinforcement schedule. For Group ITN-1, three of the six daily reinforced trials were followed by one nonreinforced placement. Group ITN-3 received an N-length placement of three following one of the six reinforced running trials. The reinforcement schedules for all groups may be seen in Table 1 .

After acquisition training, all subjects received 6 extinction trials/day for 3 days, a total of 18 extinction trials. The procedure for extinction trials was the same as for nonreinforced trials during acquisition (for the ITN groups, placements were discontinued during extinction).

The subjects were run in squads of three, one from each group in a squad, with an intertrial interval of $3 \mathrm{~min}$ in both acquisition and extinction.

\section{Results and Discussion}

Acquisition. The data from the last day of acquisition were combined into a single block and analyzed. As can be seen in Figure 2, the differences between the three groups at the end of acquisition (Point A) were relatively small. This observation was confirmed by a one-way analysis of variance that indicated no significant differences between the three groups $(F<1)$.

Extinction. From Figure 2, it is clear that Group ITN-3 was more resistant to extinction than Group ITN-1. The results of a 3 (groups) by 18 (trials) analysis of variance on the extinction latencies support these observations. The main effect for groups was significant $[F(2,27)=27.29, \quad p<.001]$, and the subsequent planned comparisons indicated that Group PRF was more resistant to extinction than Group ITN-3

Table 1

Acquisition Schedules for Running Trials and Placements for Groups PRF, ITN-1, and ITN-3 in Experiment 2

\begin{tabular}{cccc}
\hline & PRF & ITN-1 & ITN-3 \\
\hline Day 1, 5 & RNRNNR & RnRRnRRnR & RRRnnnRRR \\
Day 2, 6 & RRNNNR & RRnRRnRnR & RRRRnnnRR \\
Day 3, 7 & RNNRNR & RnRnRRRnR & RRnnnRRRR \\
Day 4, 8 & RNNNRR & RRnRnRRnR & RnnnRRRRR \\
\hline
\end{tabular}

Note $-R=$ reinforced trial $;=$ nonreinforced trial; $n=$ nonrein forced placement.

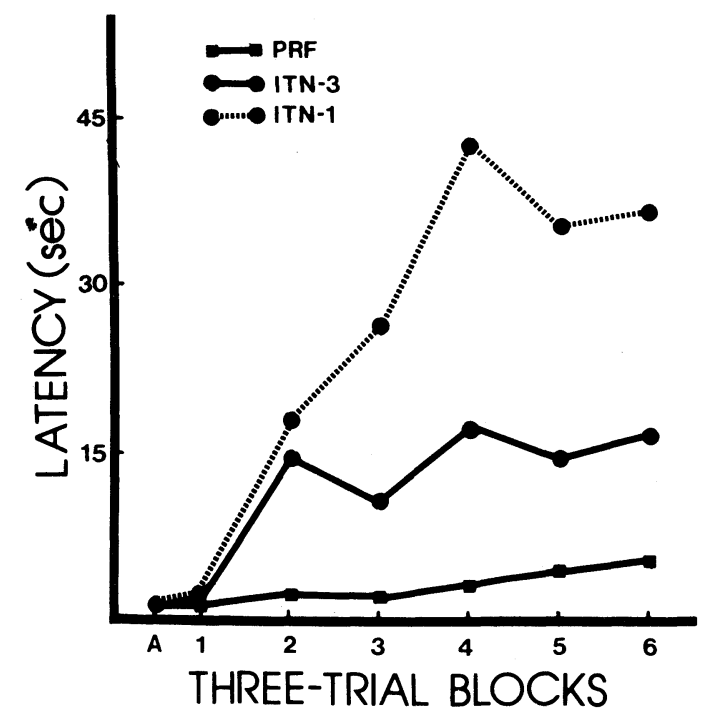

Figure 2. Extinction response latencies in three trial blocks for the PRF, ITN-3, and ITN-1 groups following extended acquisition (Experiment 2).

$[t(18)=4.97, p<.001]$, and that Group ITN-3 was more resistant than Group ITN-1 [t $(18)=3.29, \mathrm{p}<.01]$. Thus, the groups were ordered, in terms of resistance to extinction, as follows: PRF $>$ ITN-3 $>$ ITN-1. The significant Groups by Trials interaction $[\mathrm{F}(34,459)=2.25$, $\mathrm{p}<.001]$ indicated that these differences progressively increased across extinction trials. In the present experiment, then, following extended training, long placement $\mathrm{N}$-lengths generated greater $R_{n}$ than did short $\mathrm{N}$-lengths. The main effect for trials was also significant $[F(17,459)=7.38, p<.001]$. These data are analogous to those collected in similar running trial experiments (cf. Capaldi, 1967) and provide further support for the hypothesis (Capaldi, 1971) that $R_{n}$ is determined by placement sequence in much the same way as it is by sequence of reward on running trials.

\section{GENERAL DISCUSSION}

The data from both experiments demonstrate that both short and long placement ITN-lengths result in an increase in $R_{n}$ compared to that generated by CRF alone. In addition, ITN-length was also shown to interact with level of acquisition in determining $R_{\mathbf{n}}$. Specifically, in Experiment 1, under conditions of limited acquisition, the groups were ordered PRF $>$ ITN-1 > ITN-3 = CRF (i.e., short ITN-lengths generated greater $R_{n}$ than long ITN-lengths); and, in Experiment 2, when extended acquisition was employed, the groups were ordered PRF > ITN-3 > ITN-1 (i.e., long ITN-lengths generated greater $R_{n}$ than short ITN-lengths).

Therefore, the findings of the present studies suggest that placement $\mathrm{N}$-lengths operate to increase resistance to extinction in a manner very similar to that generated by $\mathrm{N}$-lengths that occur on running trials. The sequential explanation (Capaldi, 1967) of these results is as follows: Resistance to extinction is a function of two variables, (1) the habit strength of the theoretical $\mathrm{SN}_{-} \mathrm{R}_{\mathrm{I}}$ association, an association formed whenever a N-R transition occurs and (2) N-length. Habit strength of the $S^{N}-R_{I}$ association is determined by two variables, (1) number 
of $N-R$ transitions and (2) reward magnitude on the $R_{I}$ trials of the $S^{N}-R_{I}$ association. According to the sequential hypothesis, after limited acquisition training a group receiving $\mathrm{N}$-lengths of 1 should be more resistant to extinction than a group receiving $\mathrm{N}$-lengths of 3 . Since the strength of the hypothetical $\mathrm{S}^{\mathrm{N}}-\mathrm{R}_{\mathrm{I}}$ association would not be asymptotic for either group, but the reward magnitude of the $R_{I}$ trials of $\mathrm{S}^{\mathrm{N}}-\mathrm{R}_{\mathrm{I}}$ connection is equated for all groups, in the present paradigm resistance to extinction following limited training would thus be a function of the number of $N-R$ transitions. Therefore, Group ITN-1, which received more N-R transitions than Group ITN-3, would be predicted to be the more resistant to extinction of the two groups (as was found in Experiment 1). On the other hand, after extended acquisition training, a group receiving $\mathrm{N}$-lengths of 3 should display more resistance to extinction than a group receiving $\mathrm{N}$-lengths of 1 . Following extended training the strength of the hypothetical $S^{N}-R_{I}$ association would be asymptotic for both groups. According to sequential theory, resistance to extinction would thus be, in the present extended acquisition procedure, a function of N-length. Since Group ITN-3 received longer placement N-lengths than Group ITN-1, ITN-3 would be predicted to be more resistant to extinction (as was found in Experiment 2).

Thus, the present data indicate, in agreement with Capaldi (1971), that sequence of reinforcement-nonreinforcement events on placements is an important determinant of extinction performance in certain instrumental learning situations. This contention also receives support from collateral studies that have shown that schedule of placements is an important determinant of performance during acquisition (Homzie, Gohmann, \& Hall, 1971; Homzie \& Rudy, 1971; Seybert et al., 1976; Seybert, Mays, Littlejohn, Mellgren, \& Haddad, in press).

It must be noted, of course, that the present conclusion that a sequential mechanism underlies the operation of ITN would seem to be discrepant with our previous findings (Seybert et al., 1977). These data indicated that a generalization decrement process might be responsible for the effects of ITN. We also, however, suggested extreme caution in consideration of that conclusion, for several reasons (see Seybert et al., 1977, for further elaboration). While the present findings suggest that we were correct in our reticence to accept the conclusions implied by our earlier findings, these data fail to provide information regarding possible reasons for the discrepancy. Hopefully, further research will provide such a solution.

\section{REFERENCES}

BRown, R. T., \& Logan, F. A. Generalized partial reinforcement effect. Journal of Comparative and Physiological Psychology, 1965, 60, 64-69.

CAPaldi, E. J. A sequential hypothesis of instrumental learning. In K. W. Spence \& J. R. Spence (Eds.), The psychology of learning and motivation: Advances in research and theory (Vol. 1). New York: Academic Press, 1967.

CAPALDI, E. D. Effect of nonrewarded and partially rewarded placement on resistance to extinction in the rat. Journal of Comparative and Physiological Psychology, 1971, 76, 483-490.

Homzie, M. J., Gohmann, T., \& Hall, J. W. Runway performance in rats as determined by the predictive value of intertrial reinforcements. Journal of Comparative and Physiological Psychology, 1971, 74, 90-95.

HomzIE, M. J., \& RUDY, J. W. Effect on runway performance of reinforcement contingencies established to empty goal-box placements. Learning and Motivation, 1971, 2, 95-102.

Seybert, J. A., Gerard, I. C., Myers, J. F., Baer, L. P., \& Clipper, R. C. Effects of intertrial partial reinforcement and level of acquisition on resistance to extinction. Bulletin of the Psychonomic Society, 1976, 8, 7-9.

Seybert, J. A., Mays, M. Z., Littlejohn, R. L., Mellgren, R. L., \& Haddad, N. F. Differential runway performance using goalbox placements and running trials as discriminative stimuli. Quarterly Journal of Experimental Psychology, in press.

Seybert, J. A., Vandenberg, G. L., Wilson, M. A., \& GERARD, I. C. Effects of intertrial nonreinforcement (ITN) in instrumental escape conditioning. Bulletin of the Psychonomic Society, 1977, 10, 39-42.

(Received for publication January 10, 1978.) 